\section{A NATIONAL DEPARTMENT OF HEALTH.}

To THE EDItor of Scrence-In the excellént article on 'The Progress and Achievements of Hygiene,' in your issue for November 26th, there is an error of omission which, whether intentional or not, should not be allowed to pass uncorrected in a journal so prominent as ScIENCE.'

On page 796 the writer says : "Since Congress has failed to act upon the President's repeated recommendation and the petitions of numerous medical societies for the creation of a National Health establishment, there is no good reason why the scope of duties and powers exercised by the Marine Hospital Service should not be enlarged ;". making no allusion, whatever, to the comprehensive bill recently drawn up by the American Medical Association, to be urged before the present session of Congress.

The bill, as formulated, provides for an independent department, of which the Marine Hospital Service shall constitute, as it should, a subordinate bureau.

The conservation of the public health, considered even from a purely economical standpoint, is of national importance and should be relegated to no subordinate bureau with or without ' an advisory board.' To do so would be to postpone, perhaps for decades, the imperative and rational step which should be taken now.

The head of the new department ought to be made a cabinet adviser, but perhaps this may not be at present. If necessary, the Constitution can and will in time be altered to give it additional powers consonant with the requirements of modern sanitary science. To quote Dr. Girdner in the North American Review for the present month, what is needed is : "A unifying and supervising force in the national government which will direct, harmonize and render efficient the agencies of the various States."

\section{H. Preston.}

DAVenport, December 7, 1897.

\section{SCIENTIFIC LITERATURE.}

Habit and Instinct. By C. Lloyd MorgaN. London, Edward Arnold. 1896. 8vo. Pp. 352. This is a work on comparative psychology largely based on observations of bird life, and containing appropriate speculations concerning the origin and development of certain mental phenomena. The press work is excellent, the one illustration fair and the binding poor.

In the preface Professor Morgan makes a gracious allusion to those whom he met during his lecture tour, and he shows throughout the entire book an appreciation of, and a remarkable familiarity with, the work of American biologists. This may be due to the fact that 'Habit and Instinct' is the embodiment, in book form, of a series of lectures delivered in various university center's of the United States; but one experiences an exhilarating sensation of novelty in reading a book on modern biological problems which is neither supported by the legs of Lord Morton's mare nor infested with bob-tailed mice and epileptic guinea pigs.

First, defining his use of such terms as habit, instinct, reflex action, connate and deferred activities, automatism, etc., he divides the animal activities into those which are inherited and those which are acquired. From the biological point of view, habits are acquired activities of the individual, while instincts are congenital activities not characteristic of the individual alone, but of all the members of the group to which the individual belongs.

The first third of the book is largely descriptive of the habits of young birds and mammals, the birds"in particular being selected from representative groups. The anecdotes are told in a most entertaining manner, but one fears that, as the embryologist drew many false conclusions from data supplied by the highly specialized meroblastic egg of the hen, so the comparative psychologist may be deceived by the data furnished by the highly specialized mental equipment of the bird. Though the observations would doubtless prove less entertaining, it is in the lower rather than in the higher vertebrates that one would search for the more simple and less involved mental phenomena. The anecdotes are generally pertinent, but a half page of speculation as to how a pig would jump out of a chair is neither instructive nor conclusive.

Having arranged his data, Professor Morgan really begins his work in the sixth chapter, 
where he maintains that the first instinctive act (for example, the first peck of a newly hatched chick), the more automatic result of an inherited motor coordination, supplies to consciousness its first experience-data. "This is due to complex groups of incoming currents, from the parts concerned in the response, along afferent nerves to the sensorium." On this first occasion the consciousness arises wholly by backstroke.' "On subsequent occasions, under associative suggestion, revivals in consciousness of previous experience-data modify the whole process and introduce the effective guidance of consciousness," ** and ** "This profiting by individual experience is of the very essence of intelligence."

If the revivals in consciousness are pleasurable the activity is augmented; if unpleasant or painful it is inhibited. The repetition of the act becomes; then, a matter of conscious choice, and through reiteration the action becomes ingrained and habitual. "On this conscious selection and choice depends $* * *$ the development of those habits which are acquired as opposed to those which are congenital; and *** the whole mental as contrasted with merely biological evolution."

In treating of imitation, while it is admitted that there may be imitative organic response, independent of experience, the incentive to intelligent imitation is the pleasurable sensation which the imitator receives when his acts resemble the acts of others. The tendency to imitate is thus based on an innate proclivity, and is the means of securing to the organism a congeries of acquisitions which, perfected through repetition, may finally become habitual. In the opinion of Professor Morgan, already expressed in an earlier work, the value to the organism of the imitative tendency is vital. On its presence the questions of survival or destruction frequently depend, for the imitation of the quick-witted and alert is often the salvation of the more stupid. In gregarious animals, through 'tradition,' acquisitions are handed down from generation to generation without the aid of hereditary transmission.

The motif in the chapter on 'Emotions' is the elaboration of the theory of James, namely, that the emotion originates, is primarily gen- erated, by a back-stroke from the motor organs and viscera, and thus 'all the data of sense experience are of peripheral origin.' Though Morgan's observations appear to be in accord with this view, the reader may not feel thoroughly convinced that the emotions are universally the conscious effect of the back-stroke from the visceral actions.

In the succeeding chapter the author shows that though an emotion is private to, and exclusively for, the individual receiving the backstroke, the subsequent 'expression' may be, and often is, an indication to others of the particular emotional state. "So long as the expression indicates an emotional condition which shows that the animal means business, that is enough from the biological point of view." $\mathrm{He}$ thus incidentally reconciles Wallace's theory of exuberant vitality with commonplace sexual selection. Exuberance of vitality may be expressed, on the one hand, by emotion (song, etc.), and, on the other, by peculiarities of structure (plumes, etc.). Both may be of varying potency in arousing the sexual instinct of the opposite sex, and thus of varying selective value. "Stripped of all of its unnecessary æsthetic surplusage, the hypothesis of sexual selection suggests that the accepted mate is the one that most strongly evokes the pairing instinct."

The view is advanced that the song of birds, unlike their calls and alarm notes; may be 'traditional' and due to imitation; and the question of the instinctive nature of the peculiar antics and aërial evolutions of certain birds, before and during the breeding season, is raised. But ' in all these matters further and fuller evidence from direct observation is to be desired.'

The sordid questions of domestic economy, nest-building, incubation, the care of young, etc., are now discussed and the questions raised : Are these phenomena instinctive or are they intelligent? Are they congenital or are they the result of individual experience? If instinctive, are they attributable to natural selection alone, or to the inheritance of acquired habit? So far as certain of the phenomena are concerned, the author favors a possible cooperation of natural and intelligent selection, though he concludes that as matters stand 'the ques- 
tion must be left open.' Questions arising in connection with the migratory habit are left in a similar way.

Professor Morgan now lays special stress upon consciousness as a cooperating factor in organic development. In the earlier chapters it was assumed, for the sake of simplicity, that mental evolution might be concomitant with, rather than a factor of, organic evolution. His presentation of the difference between organic evolution as a result of the elimination of the unfit, and of organic evolution as a result of conscious choice, through the elevation of the fit, is extremely ingenious, and the part that the latter may play in the struggle for existence is clearly shown. "In so far as conscious adjustment aids in the struggle for existence, in so far through it the animal is better able to escape danger, to secure a more favorable habitat, to gain a mate and beget progeny ; the animal possessed of intelligence will escape elimination, transmit his power of conscious adjustment, and contribute to the propagation of his race. Without fully subscribing to the doctrine of the all-sufficiency of natural selection, we may yet say that natural selection will exercise a determining influence in deciding the course which conscious adjustment must take."

The question of the inheritance of acquired habits is many times raised, but receives no partisan treatment in the first three hundred pages. In the latter part of the book the author instinctively holds to his earlier belief, while admitting, as a result of his experience, certain intelligent modifications of his views. We quote from page 305 :

"If pressed to summarize my own opinion on this question, I should say : First, that there is but little satisfactiory and convincing evidence in favor of transmission, but that variation does seem in some cases to have followed the lines of adaptive modification, so as to suggest some sort of connection between them; secondly, that there are many instincts relatively definite and stable which may fairly be regarded as directly due to natural selection, though here again, if we could accept the view that adaptive modification marked out the lines in which congenital variation should run, our conception of the process of their evolution would be so far simplified; thirdly, that there are some peculiar traits, also seemingly definite and stable, which can only be attributed to the indirect effects of natural selection."

In the discussion of modifications and variations the author follows Mark Baldwin in defining the former as acquisitions which occur in the course of individual life, and the latter as those changes in the individual which are the result of some disturbance in the germinal substance. Mental phenomena are laid aside for a time and the more easily apprehended arguments and illustrations from structure adopted. The author dwells at considerable length upon the claims of the extreme Neo-Darwinians, on the one hand, and the extreme Neo-Lamarckians, on the other, and concludes that "all this is very interesting, and affords considerable scope for ingenuity. But it does not touch the question at issue, and this is, not which method is apparently the most advantageous; not which method we should have adopted had the work of creation been entrusted to our care, but which has been adopted by nature." Weismann's principles of germinal and intra-selection, Baldwin's organic selection and the author's innate plasticity indicate the neutral ground where selectionists may meet transmissionists ; where fortuitous variations may finally take the place of mere temporary adaptive modifications.

Professor Morgan's entertaining style, his originality of experiment, his quick interpretation, his rare quality of explanation and the comparative novelty of his subject will give 'Habit and Instinct' a place beside 'Animal Life and Intelligence' in the library of every working biologist. HERMoN C. Bumpus.

Das Nördliche Mittel-Amerika, nebst einen Ausflug nach den Hochland von Anahuac. Von Dr. CARL SAPPer. Braunschweig, Vieweg und Sohn. 1897. With maps and illustrations. Pp. 436.

The studies of Central American geography and ethnography which Dr. Sapper has contributed to Petermann's Mittheilungen, Globus and other periodicals, from time to time during the last ten years, have made his name familiar to all interested in the products and history of that portion of our continent. In the volume 